\title{
Foreign Body in Vagina - An Unusual Presentation
}

\author{
Pooja Kumari¹, Bhawana B. Lakhkar², Sachin Damke ${ }^{3}$ Sham Lohiya ${ }^{4}$
}

\begin{abstract}
1Department of Paediatrics, Jawaharlal Nehru Medical College, Sawangi (M), Wardha, Maharashtra, India. 2Department of Paediatrics, Jawaharlal Nehru Medical College, Sawangi (M), Wardha, Maharashtra, India. 3Department of Paediatrics, Jawaharlal Nehru Medical College, Sawangi (M), Wardha, Maharashtra, India. ${ }^{4}$ Department of Paediatrics, Jawaharlal Nehru Medical College, Sawangi (M), Wardha, Maharashtra, India.
\end{abstract}

\section{INTRODUCTION}

Foreign bodies in the vagina in paediatric population are not commonly suspected. The presentation of such cases is similar to that of pathological diseases of cervix and the vagina like vaginitis and cervicitis which are more common. Infections of young female genital tract are common because of higher $\mathrm{pH}$, relatively low oestrogen level and unfavourable bacterial flora.(1)

Foreign bodies in the vagina are usually introduced accidently and history is negative. Patients commonly present with blood stained discharge, foul smelling pus, pain in the abdomen, dysuria or constipation. Symptoms secondary to vaginal foreign body account to $4 \%$ of paediatric population visiting gynaecological OPD as reported by Dahiya et al. ${ }^{(2)}$ In girls $<6$ years of age, who underwent examination under general anaesthesia, aetiology of vaginal discharge in $45 \%$ of the cases was found to be foreign body. He has suggested that it is becoming important in most settings to organize special gynaecology clinics for pre-pubertal girls in order to develop special knowledge and skills needed in paediatric gynaecology. Here we report a case of prepubertal girl with vaginal foreign body not responding to medical line of management (antibiotics), rendering further evaluation for vaginal discharge. Unusual scenario in this report is a simple case which remained undiagnosed for one year. Another issue was absence of mother from the scene and constant denial by father to bring her which raises the suspicion of sexual abuse.

\author{
Corresponding Author: \\ Dr. Pooja Kumari, \\ Department of Paediatrics, \\ JNMC, Sawangi (M), Wardha, \\ Maharashtra, India. \\ E-mail: pooja12690@gmail.com
}

DOI: $10.14260 / j e m d s / 2020 / 540$

How to Cite This Article:

Kumari P, Lakhkar BB, Damke S, et al. Foreign body in vagina - an unusual presentation. J Evolution Med Dent Sci 2020;9(34):2487-2489,

DOI: $10.14260 /$ jemds/2020/540

Submission 18-04-2020,

Peer Review 15-07-2020,

Acceptance 21-07-2020,

Published 24-08-2020.

Copyright (C) 2020 JEMDS. This is an open access article distributed under Creative Commons Attribution License [Attribution 4.0 International (CC BY 4.0)] 


\section{PRESENTATION OF CASE}

A 6-year-old female child was admitted in paediatric ward of AVBR hospital, a unit of Datta Meghe Institute of Medical Sciences, with chief complaint of blood-stained discharge from vagina since 1 year.

Patient had history of trauma over the abdomen around 1 year back following which the complaint started. The spotting was present daily. The discharge was blood stained and foul smelling. No history of abdominal pain, urinary discomfort, local pain or swelling could be obtained. History of sexual abuse or family discordance was denied. No history of bleeding from any other site. Mental status and activities were normal. On examination, general condition, vital parameters were normal. Child was pale with no evidence of skin bleeds. There were no signs of precocious puberty, trauma or inflammation locally (for child abuse). Systemic examination was normal. Hemogram (Haemoglobin 12.6 gm / dl, TLC 10000 / cumm, PLT - 4.52 L / cumm) and bleeding parameters (PT - 13 sec, APTT - 30 sec, INR - 1) were normal. Liver function tests, urea, creatinine, electrolytes and endocrine work up were normal. X ray was done to confirm bone age which was normal. USG of abdomen and pelvis was done 3 times ( 2 times outside and 1 at our hospital) which was reported normal (may be because the echogenicity of the foreign body was same as normal vaginal tissue). CT scan of genitourinary tract (done outside) was also normal.

For the same complaint patient was been investigated previously. Total and differential count, liver function test, kidney function test, and coagulation profile were normal. Gynaecology opinion was taken and vaginal examination under short general anaesthesia was done. Three to four dried mud pieces of $1 \times 1 \mathrm{~cm}$ in size were extracted from vagina. The spotting stopped after the procedure.

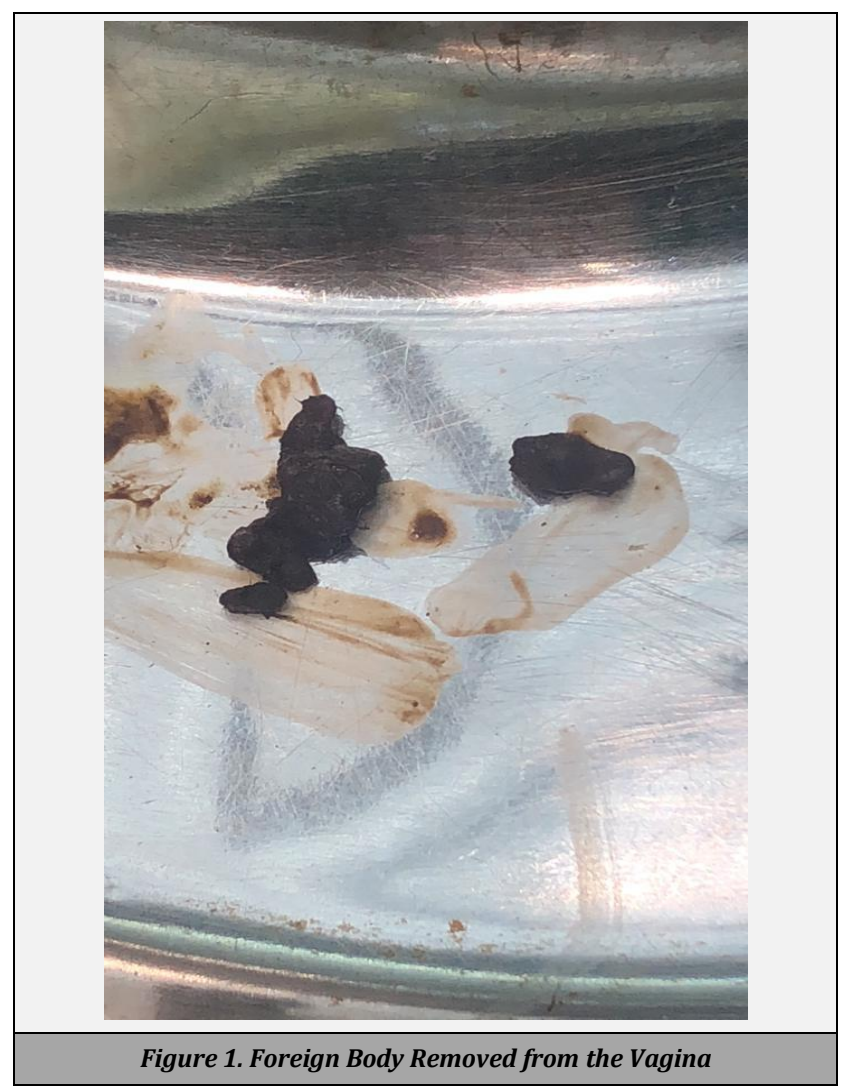

\section{DISCUSSION OF MANAGEMENT}

Gynaecology opinion was taken and vaginal examination under short general anaesthesia was done and 3 - 4 muddy stones of $1 \times 1 \mathrm{~cm}$ in size were extracted from vagina.

\section{DISCUSSION}

The most common cause for vaginal discharge is usually vulvovaginitis. In a study done in our institute in women of reproductive age Candida vulvovaginitis was found in $63 \%$ of women in reproductive age.(3) Fungal vulvovaginitis is common in children also as can be seen in outpatient department. Blood stain discharge can be found as child keeps on scratching.(4)

Foreign bodies found in the vagina in paediatric population are of different variety. These can be toilet paper, toys, stones etc.(5) The possibility of sexual abuse should always be kept in mind. The history and examination should be directed for such events. $(6,7)$ Closson et al reported two girls with vaginal foreign body both denied any possibility of sexual abuse but vaginal culture of both girls grew N. Gonorrhoea.(8) In our patient also history of sexual abuse was denied. As Culture of discharge was sterile, it was not helpful. Inability of father to bring mother kept index of suspicion very high.

In this case, 3 to 4 small muddy lumps of size $1 \times 1 \mathrm{~cm}$, were removed, children of this age have curiosity to explore the body openings. The most common foreign bodies are found in nose followed by ear, airways and vaginal opening.(2) In the present case foreign body remained in vagina for more than one year and was missed with ultrasonography and CT scan also. The continuous flow vaginoscopy can be used to detect an intra-vaginal foreign body, which may then be removed successfully by hysteroscopy. Hysteroscopy is safe, convenient, effective and easy to perform, even in a child. In the index patient, examination under anaesthesia and removal of the foreign body with retractor. $(9,10)$

According to Herman Giddens, the age for foreign body ranged from 2.6 to 9.2 years.(6) The most common symptom was blood stained vaginal discharge/vaginal bleeding (49\%). Duration of symptoms varied from 1 day to 2 years. In his study, fifty four percent of the patients recalled insertion of the foreign object, usually by the girl herself. All but three patients (91\%) either recalled insertion of the foreign object and/or had vaginal bleeding or blood stained or foul vaginal discharge, and or visualization or palpation of the foreign body in physical examination. Symptoms resolved after removal of the foreign body.

Author's view regarding vaginal foreign body is vaginitis could result in ulceration of the vaginal walls, which may involve neighbouring structures causing urinary and faecal fistulae. The diagnostic investigations commonly used are USG pelvis, CT/MRI pelvis and vagino-hysteroscopy which can be therapeutic. Take home message from this case is exploration for vaginal foreign body should not be avoided in any child presenting with vaginal discharge. High index of suspicion should be kept for possibility of sexual abuse.

Financial or Other Competing Interests: None. 


\section{REFERENCES}

[1] Abdessamad HM, Greenfield M. Vaginal foreign body presenting as bleeding with defecation in a child. J Paediatr Adolesc Gynecol 2009;22(2):e5-7.

[2] Dahiya P, Sangwan K, Khosla A, et al. Foreign body in vagina: an uncommon cause of vaginitis in children. Indian J Paediatr 1999;66:466-7.

[3] Bhute AA, Jha RK. Pharmacoepidemiological perspective of vaginal candidiasis: a cross sectional surveillance study among women of reproductive age group belonging to Wardha district, Maharashtra, India. Res J of Pharm Bio Chem Sci 2016;7(1):499-511.

[4] Ologe FE, Dunmade AD, Afolabi OA. Aural foreign bodies in children. Indian J Paediatr 2007;74(8):55-8.
[5] Stool SE, McConnel CS. Foreign bodies in paediatric otolaryngology. Some diagnostic and therapeutic pointers. Clin Paediatr (Phila) 1973;12(2):113-6.

[6] Herman-Giddens ME. Vaginal foreign body and child sexual abuse. Arch Paediatr Adolesc Med 1994;148(2):195-200.

[7] Stricker T, Navratil F, Sennhauser FH. Vaginal foreign bodies. J Paediatr Child Health 2004;40(4):205-7.

[8] Closson FT, Lichenstein R. Vaginal foreign bodies and child sexual abuse: an important consideration. West J Emerg Med 2013;14(5):437-9.

[9] Nayak S, Witchel SF, Sanfilippo JS. Vaginal foreign body: a delayed diagnosis. J Paediatr Adolesc Gynecol 2014;27(6):e127-9.

[10] Wang WC, Lee, CL, Soong KY. Hysteroscopic extraction of a vaginal foreign body in a child. J Am Assoc Gyn Lap 1996;3(3):443-4. 